\title{
LOS USOS POLÍTICOS DE LA REPUTACIÓN EN LA CORTE DE FELIPE IV ${ }^{1}$
}

\begin{abstract}
Cassio: Reputation, reputation, reputation! O! I have lost my reputation. I have lost the immortal part of myself, and what remains is bestial. My reputation, Iago, my reputation!

Iago: ... Reputation is an idle and most false impostition; oft got without merit, and lost without deserving: you have lost no reputation at all, unless you repute yourself such a loser. ${ }^{2}$
\end{abstract}

En su artículo "A question of reputation?" Elliott comenta que, en relación a asuntos exteriores Policies of reputation, retreat, and retrenchment all constitute possible responses for a great imperial power which perceives itself under threat and interests, and in laying bare the motivations, will make a contribution to the understanding of the historical process that extends far beyond the history of Spain alone. ${ }^{3}$

Al comentar el trabajo de Elliott -y también en un contexto internacional- Stradling dice que "Elliott defined [reputación] as a unique meld of ideals to do with prestige and honour" 4 . Esta hipótesis dice, "has to some extent had the effect of obscuring the primary reality of the religious commitment which lay behind, and produced, reputación." 5

Moviéndome desde el contexto internacional de la reputación, y su influencia en los asuntos exteriores, tengo la intención de explorar sus usos e influencia en asuntos rutinarios domésticos. Me gustaría examinar este texto del "Othello" de Shakespeare, citado arriba, como una lanzadera para dar luz a la percepción del siglo diecisiete de la reputación aquí. ¿Cuál de las dos quiere que tomemos? ¿o quiere que tomemos las dos?

Cassio dice que su reputación es la "immortal part" de sí mismo. En la teología del siglo diecisiete la creación del hombre tenia dos origenes: el humano y el divino. El cuerpo era la contribución del hombre, el alma la de Dios. "La vida comienza con el alma y termina, no con su final, sino con su separación del cuerpo, mera materia." ${ }^{2}$ Lo que parece que Cassio dice, por lo tanto, es que su reputación era su alma - la parte inmortal, y su alma creación de Dios. Cuando Cassio pierde la reputación, pierde el alma. Está condenado a la perdición.

lago responde a Cassio que no debe ser tan dramático; la reputación es una imposición falsa. Una imposición es una decepción; una reputación, por lo tanto, una quimera, una invención, impuesta a la persona real, no por causa de sus méritos, sino indiscriminadamente. Eso nos ofrece dos interpretaciones: la primera, que la persona decepciona al mundo con su reputación, que es falsa; y la segunda que el mundo cree, o no, en una reputación sin razón. Adicionalmente Iago nos informa que "you have lost no reputation at all, unless you repute yourself such a loser." Si no se admite que es verdad que la reputación se ha perdido, no se ha perdido. Volvemos a la frase inicial: que una reputación es una decepción - una imposición falsa.

Para descubrir cuales de las definiciones de la reputación de Shakespeare eran más comunes en el siglo diecisiete examinaremos tres sucesos de los años 1646 y 1647 de la Corte de Felipe IV de España. El primero de estos tres sucesos se relaciona con las negociaciones matrimoniales llevadas a cabo entre el privado Luis de Haro y su mujer doña Catalina Fernández de Córdoba ${ }^{7}$ con don 
Antonio Juan Luis de la Cerda, séptimo Duque de Medinaceli. En un principio debemos entender las posiciones políticas de los dos hombres en 1646 cuando las negociaciones empezaron.

En 1646 el intento de Luis de Haro para reemplazar a Olivares como el nuevo valido de Felipe IV estaba incompleto. Su control sobre las redes de patronazgo de la Corte dependía, todavia, en gran parte, de la influencia de su tio el Conde de Castrillo. Para que Haro pudiera consolidar su poder necesitaria el respaldo político de un mayor número de "brokers" del poder que por entonces tenía. Sin embargo, había logrado, con bastante éxito, en los tres años anteriores manipular y aventajar a sus rivales politicos. Aparte de su tío, a quien no controlaba totalmente, podia sentirse el principal contendiente.

Medinaceli, como patrón de Quevedo, había sido conocido en los años 30 como un adversario de Olivares. Todavía, en 1646, le consideraban un oponente de la existencia de los validos. En realidad, uno de los aliados más cercanos en la grandeza de Medinaceli, fuel el Duque del Infantado. A Rodrigo Díaz de Vivar de Mendoza y Sandoval, ${ }^{8}$ séptimo Duque de Infantado, se le habia relacionado en 1644 con un grupo que queria expulsar a Haro del poder. En 1641 los Duques de Infantado y los Duques de Medinaceli habian formalizado un contrato de matrimonio para sus primogénitos, Rodrigo Díaz de Vivar de Mendoza, Conde de Saldaña, y doña Antonia Maria de la Cerda. A finales de septiembre de 1646 el destino lo ofreció una buena jugada a Haro y el Conde de Saldaña murió en Madrid a la edad de catorce años.

Haro sacó provecho de esta oportunidad iniciando unas negociaciones para casar a su hijo primogénito, Gaspar de Haro, Marqués de Liche, con Antonia Maria de la Cerda. La habilidad de Haro para casar a su hijo con una hija de una de las familias más antiguas y de mayor grandeza, le daria la reputación de ser omnipotente en la política.

Era importante en el mundo político no sólo que un hombre se casara por razones dinásticas, sino también que tuviera una esposa capaz de llevar sus asuntos durante sus ausencias. Igual que la Reina, Isabel de Borbón, la mujer de Luis de Haro, doña Catalina Fernández de Córdoba, se encargaba de los asuntos de su marido con bastante éxito.

Una de las principales obligaciones del matrimonio del siglo diecisiete era la de engendrar un heredero varón. La muerte de la Reina en 1644 no provocó una necesidad urgente en Felipe IV para que se volviera a casar. La muerte de Baltasar Carlos en 1646 lo hizo imperativo. Una hija de diez años no se consideraba suficiente para asegurar la sucesión. La sobrina de Felipe, la Archiduquesa Mariana de Austria se habia prometido para casarse con Baltasar Carlos. Con la muerte de éste se la convirtió en esposa de Felipe IV. Como ya mencionamos Rodrigo Díaz de Vivar de Mendoza, Conde de Saldaña, se murió un poco antes que Baltasar Carlos en septiembre de 1646. El 28 de mayo de 1647 Oviedo escribió a fray Pedro:

anoche apretó el mal a mi Sra la Duquessa del Infantado de modo que le dieron el santíss[im]o sacramento a prissa y después la tuvieron por muerta, oi estuvo algo mejor pero esta tarde que io estuve allá temian mucho de la hora del crecimiento. Pocos son treinta y cuatro años para morir y para que la sucesión se halla conveniencia. Don Luis de Lauri ${ }^{9}$ y otros me hablaron allí en mi Sr $r^{a}$ Doña Antonia y traen el exemplar del Príncipe n[uest]ro s[eño]r y de su Mag[esta]d. ${ }^{10}$

Una de las cosas que más sobresale de esta carta, desde un punto de vista del siglo veinte, es la total falta de sensibilidad hacia los muertos y los agonizantes que muestra, y el sistema de valores tan distinto que existía. La muerte no era tna importante como la sucesión. Fray Pedro se percató de esta cuestión:

lo mismo me avia ofrecido que es gén[er]o de desdicha llegar a estado o punto las cosas, que los que avian de sentir la muerte la tengan por medio de mayores conveniençias. ${ }^{11}$ 
Doña María de Silva, Duquesa del Infantado, había tenido dos hijos que sobrevivieron la infancia, pero es obvio que había sufrido algún accidente o enfermedad que le impedía tener más hijos. Fray Pedro añadió a su comentario sobre Antonia que "bien probable pareçen estos discursos salvo que si no está despedido lo de Liche no dexará de hacer reparo." 12

El contrato hecho en 1641 entre Medinaceli e Infantado proponia la dote de Antonia asi:

En primer lugar que su ex[celenci]a el Duque de Medina ${ }^{13}$ dará en dote a la dicha su hija cien

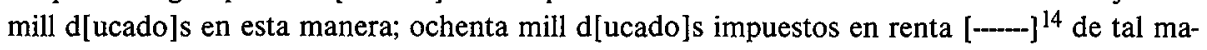
nera [------] que rindan $4 \mathrm{Vds}$ en cada un año de buena calidad. - Mas dará el dicho Duque 20V ds q[ue] restan en Joyas y vestidos. ${ }^{15}$

Saldaña era el heredero de un ducado; Liche un marqués. Por consideraciones puramente dinásticas el enlace con Liche era inferior al de con Saldaña. Como consecuencia, resultó algo sorprendente que Haro quisiese una dote de "cien mil d[ucado]s bien situados en renta" ${ }^{16}$ Además la dote no deberia incluir ni joyas ni vestidos:

porque dicen que tienen todo lo que es menester de esse género ... y replicando mi Sra la Marquessa [de Ladrada] ${ }^{17}$ de que tendría algunas Joias de $\mathrm{mi} \mathrm{Sr}{ }^{a}$ la Duquessa [de Medinaceli] ${ }^{18}$ que esté en el cielo, dio a entender que no, sino los cien mill [ducado]s. ${ }^{19}$

Don Francisco de Oviedo al comentar esta noticia a fray Pedro, escribió que:

Quando se atiende a cossa tan importante como cassar bien un hijo heredero no parece se avía de reparar mucho en que fuess desta calidad o aquella, sino que sonase se avia hecho lo que con las hijas de los más grandes $\mathrm{s}[\mathrm{eño}$ tes y más q[uan]do confiesa que tiene tanta hacienda. Pero le parece a mi $\mathrm{Sr}^{s}$ la Marquessa que según las condiciones qualquier reparo que se haga deste género bastará para deshacer el tratado aunque no esté mui adelante. ${ }^{20}$

Don Francisco era incapaz de comprender el comportamiento de los Haros al demandar términos tan específicos para el matrimonio. Nos parecería, sin embargo, que éste servía para difundir la reputación de que sus expectativas políticas eran tan grandes que permitirian tal grado de selectividad.

En $A$ la sombra de la Corona Mauro Hernández dice que mientras que el matrimonio en el siglo diecisiete, en general, era entre partidos de igual estatus, éste no era siempre una cuestión de dinero. Comenta que "habrá que tener en cuenta la categoría social de las familias y la hacienda, pero también factores como las expectativas de éxito social, las conexiones de uno y otro," 21 etc. La casa de Haro consideró obviamente que sus recursos financieros y sus expectativas politicas sobrepasaban el estatus social superior de Antonia. Ella debía, por lo tanto, compensar con un dote más grande. Captando a Antonia para su hijo tenía que hacer que Haro sonase triunfante.

En diciembre de 1646 Oviedo comentó que el matrimonio haria un "buen nudo para estrecharse." 22 No hay duda de que el matrimonio estrecharía los vínculos entre Medinaceli y Haro, pero sólo seria una ventaja para Medinaceli si la posición de Haro en el gobierno fuese segura. A principios de 1647, sin embargo, Haro se continuaba en la misma posición que había ocupado tres años atrás cuando Infantado conspiró contra él. En efecto todavía no era nada más que el ministro favorecido del Rey. El 4 de abril de 1647 Oviedo escribió:

en el negocio de mi Sr $r^{a}$ Doña Antonia su hija, Medinaceli] escribe que allá no ai principios deste casso y aunque acá se aia hablado deben de pensarlo más y que a Su Ex[celenci]a nada de lo que se habla le empeña. ${ }^{23}$

Medinaceli no estaba tan convecido del poder de Haro como para ponerse de acuerdo en todos sus deseos. Tenemos que recordar que en 1647 la amistad de Medinaceli con Infantado prevalecía por encima de cualquier negociación con Haro. Desde el punto de vista de su reputación, que 
Haro consiguiera para su hijo la niña prometida al hijo de Infantado, constituiría no sólo un triunfo político y dinástico sino también un triunfo personal.

El segundo "suceso" que vamos a investigar se complicó considerablemente por las negociaciones matrimoniales discutidas arriba. En realidad, la causa de su importancia estaba en el hecho de que la reputación fuera de suma importancia en esta esfera. El asunto tenía que ver con una señora que servía en el palacio real del Alcázar de Madrid, doña Antonia de Mendoza. Trataba de las amenazas que hacía ella para dañar la reputación de Medinaceli. El asunto nos permite ver cómo las conexiones de Medinaceli en la Corte trabajaron de parte suya para enseñar al mundo que él no se reputaba de haber perdido la reputación.

Para poder entender este asunto, primero, debemos entender que la facción de la cual Medinaceli era un miembro principal estaba a favor de mejorar la moralidad de la Monarquía Católica. Esto se veía como un medio para alcanzar una intervención favorable divina en la Monarquia. Cualquier escándalo, de sí mismo, provocaría la ira de Dios, y, además, consideraban que los pecados públicos "inficionen con su enfermedad contagiosa a los otros súbditos" 24 de la monarquia. Si un pecado no era ya público, se consideraba peor castigarlo y hacerlo más conocido que esconderlo. Cualquier escándalo público asociado con Medinaceli, además, dañaría severamente a su reputación e impediría su postura política de moralista.

Dado el estado actual de la investigación, resulta imposible establecer la naturaleza exacta de la información que doña Antonia pudiera haber usado contra Medinaceli. Sin embargo, al examinar las pistas que se dan en el epistolario entre don Francisco de Oviedo y fray Pedro de Tapia, la información siguiente llega a ser evidente. Después de la muerte de la Duquesa de Medinaceli en 1645 un familiar de Medinaceli, por aquella época residente en Cogolludo, llegó a comprometerse con doña Antonia de Mendoza. En el transcurso de la relación, se intercambiaron cartas y retratos. Durante 1646 doña Antonia estuvo demandando constantemente la devolución de los papeles y el retrato suyos a cambio de los papeles que poseía ella y su silencio.

Doña Antonia quería utilizar el asunto para abandonar su puesto en el palacio real -era Dama de la Reina-y mejorar asi su situación. La amenaza de escándalo se podría utilizar para obtener una merced de Medinaceli con la cual ella podría dejar de su puesto con dignidad. Si no sacaba provecho de la amenaza, utilizaría el escándolo mismo para dejar su puesto y manchar la reputación de Medinaceli.

En el transcurso de 1646 la facción de Medinaceli trabajó en la Corte para acceder a las demandas de doña Antonia. En septiembre de 1646 se había organizado todo lo que ella exigía y también le habían inducido a firmar un papel que absolvió al familiar de Medinaceli. El 22 de septiembre de 1646 las circunstancias instaron a fray Pedro a escribir que "parece que la mat[eri]a está fuera de peligro del ruido que se temía [que] es lo sustancial deste neg[oci]o."25

A principios de 1647 el asunto estaba complicado por las negociaciones matrimoniales de Medinaceli con Luis de Haro y con el Duque de Cardona sobre los matrimonios de los hijos varones de Medinaceli. Estas últimas negociaciones estaban dificultadas por la asociación en la Corte de doña Antonia con la familia de Benavides. Parece que esta familia utilizó su conocimiento del asunto de doña Antonia para anular las negociaciones con Cardona, con el resultado de que la hija segunda de Cardona -doña Francisca de Aragón y Sandoval- en vez de casarse con el hijo segundo de Medinaceli -don Tomás de la Cerda- se casó con el hijo de Diego de Benavides, el futuro Conde de Santisteban. Cardona se casó en segundas nupcias con la hermana de éste, doña Maria de Benavides. ${ }^{26}$ Fray Pedro comentó que el asunto con doña Antonia por entonces apareció: 
de fuerte aprehensión y todos quedaremos menos favorecidos. Antes hallo congruencias considerables de quietud y ganancia de tiempo. Más hasta ver el fin no dexaré de procurar conservar el favor. Y nunca se le desmereceré. ${ }^{27}$

Este comentario revela exactamente por qué fray Pedro y don Francisco estaban tan interesados en trabajar para preservar la reputación de Medinaceli en la Corte. Si los asuntos de Medinaceli no iban bien todos perderían influencia y posición.

A finales de marzo de 1647 Oviedo pudo escribir que "el negocio de Román ${ }^{28}$ está sosegado y se entiende que el tratado con Benavente ${ }^{29}$ está mui adelante q[ue] sería gran desahogo si se affetuase." ${ }^{30}$ A mediados de abril fray Pedro comentó que "éste caminará bien todo el tiempo q[ue] camina hacia Venabente. [sic]"31 El temperamento de la señora todavía no se prestaba a una resolución pronta. No fue hasta primeros de junio cuando don Francisco pudo decir:

el negocio de Román está en buen estado aunque la parte no se contenta con la merced de ocho mill ducados de renta. ${ }^{32} \mathrm{Y}$ en razón de honores los que quisiesse, porque aspirava a ocupación $\mathrm{u}$ officio grande y amenaza que se irá al convento de San Quirce de Valladolid ${ }^{33}$ y habló a Su Mag[esta]d quexándolse vivam[en]te. Ia con difficultad podrá volver a lo que se intentó ${ }^{34}$ y dice Su Ex[celenci]a que si se acaba este negocio con bien lo han dispuesto las oraciones de VSI. ${ }^{35}$

Fray Pedro no se quedó impresionado con las nuevas amenazas. "Si le deben estas mer[ce]des, -escribió- bien. Pero si no, muy poca fuerça me hizieran esas amenazas." 36 La señora debía de haber reconocido este argumento porque a principios de julio Pedro de Pacheco ${ }^{37}$ dijo a Oviedo:

escribiesse a San Lúcar como la parte de Román estava contenta ia con las mercedes, porque el marido de su ama ${ }^{38}$ la dixo que en materia de honores pidiesse lo que le estubiesse bien por hallarse con tan grande aprieto de hacienda y los ocho mill ds de renta q[uan]do le avian ofrecido antes se han convertido en merced de Tusón, llave de la cámara con exercicio y cuatro mill ds de renta, con esto se despachó luego proprio al hombre de Benavente que creen lo acetará, y refieren que dixo la parte de acá que si no se contentaba era señal que no queria casarse. ${ }^{39}$

En 1641, por su puesto de Dama de la Reina, doña Antonia de Mendoza recibió un sueldo de 1.800 ducados al año. ${ }^{40}$ En los papeles de su archivo en el Palacio Nacional hay uno que se refiere a la merced que le concedió el Rey "de tusón y llave de entrada para el dicho sr. Conde de [Benavente] y de 4Vds de Renta por dos bidas". 41 Éste nos confirma la identidad de la señora y las cantidades de dinero, junto con la naturaleza elevada de los honores -el Toisón era uno de los más altos honores- nos indican el daño que doña Antonia podía hacer a la reputación de Medinaceli. El 17 de mayo de 1648 el décimo Conde de Benavente, Juan Alonso Pimentel de León, se casó con doña Antonia de Mendoza en el palacio real de Madrid.

Para una persona en la posición de fray Pedro, aún más que para el Duque de Medinaceli, la reputación fue de una importancia primordial para su carera. Podemos, de hecho, decir que era la ventaja más importante que tenía. Examinaremos, por lo tanto, cómo fray Pedro cuidaba y utilizaba la reputación en su carera.

En 1646, cuando el Rey se trasladó de Madrid a Zaragoza para la campaña contra Francia, pasó por Atienza en la diócesis de Sigüenza. La tradición dictó que fray Pedro ofreciera un regalo al Rey, al reunirse con él en Atienza. Fray Pedro dio mucha consideración al asunto. Era de suma importancia elegir un regalo adecuado, tanto para agradar al Rey como para mantener la reputación de fray Pedro. La elección final cosistió en una lámina, comida y la promesa de una contribución financiera al ejercito. 
Diez días después de la reunión con el Rey, Oviedo informó que se corria la voz en Madrid sobre el exagerado valor del regalo que fray pedro había entregado al Rey:

Ha importado -escribió Oviedo- que VSI me hiciesse merced de avisar lo que avía dado a Su Mag[esta]d porque han llegado muchos curiossos con terribles disparates, unos que VSI dio $20 \mathrm{~V}$ ds en dinero para el exército otros diez y seis escudos de oro, otros dos mill f[anega]s de trigo y dos mill de cebada y ocho mill ducados ... los que han sabido la verdad les ha parecido mui proporcionada y mui justa. ${ }^{42}$

Fray Pedro estaba contento de que Oviedo hubiera podido reprimir el rumor, porque se hubiese dañado su reputación para obras pias si se le considerase una persona que hace regalos ostentosos al Rey. La reputación de fray Pedro para la santidad, el desinterés y la caridad fue, como se mencionó anteriormente, su ventaja más valiosa.

Podemos decir con certeza que la consideración de la reputación influyó en la mayoría de las acciones de fray Pedro. A diferencia de algunos obispos, fray Pedro se vio a si mismo como el administrador del dinero de su diócesis y no el dueño. Fray Pedro consideró que una de sus principales obligaciones en la administración de su diócesis era la de abastecer a los pobres. Para conseguirlo se vendia el trigo que recibía en diezmos a la tasa. En marzo de 1647 escribió a don Francisco:

lo cierto es que en mi modo de admynistrar vale un tercio menos el obispado cumplidam[en]te q[ue] valiera a otros, sólo con aver vendido en plata ${ }^{43}$ como lo hacen algunos y llebar portes subiera mucho. No llevo los dictámenes de plata y caso negado fuera tolerable no es decente en mi cosa q[ue] huela a este género de útiles. ${ }^{44}$

Como se ve, en realidad, aún para los prelados existían dos tasas - la de vellón y la de plata.

Ya que hemos examinado la postura de fray Pedro hacia el dinero, ahora veremos cómo la reputación se utilizó y se difundió en la esfera religiosa de la preparación para la muerte. El antiguo régimen se destacó por su alta tasa de mortalidad infantil. Fernando Martínez Gil en Muerte y sociedad en la España de los Austrias estima que el 50\% de los niños se morían antes de cumplir los 20 años y más o menos el $40 \%$ antes de cumplir los $10 .{ }^{45}$ Esta estadística, de alguna manera, ayuda a explicar la obsesión del siglo diecisiete por el bien morir. Como hemos visto, la muerte en la teología del siglo diecisiete consistía en "dissolutio corporis et animae." ${ }^{46} \mathrm{Se}$ consideraba de gran importancia que al morir, el alma -la contribución de Dios a la creación- estuviera suficientemente preparada. Para prepararse para la muerte y para asegurar la vida eterna del alma, era de suma importancia recibir los consejos y la dirección de un buen confesor.

Cuando el Príncipe Baltasar Carlos cayó enfermo en Zaragoza en octubre de 1646 la casualidad quiso que fray Pedro se encontrase también en la ciudad. ${ }^{47}$ Fray Pedro describió la muerte del Príncipe a don Francisco de Oviedo:

Recivió luego el viático. Y aviéndole recibido me llamó aparte estando allí su padre y habló en gran conformidad de morir ${ }^{48}$ y aunq[ue] después le volvió a subir el humor a la cabeza, siempre q[ue] le hablé de Dios y de ir a gozarle estubo atento ... Murió a las siete de la tarde y con todos los sacram[en]tos y con señales de que Dios le quiso preservar de los peligros desta vida... Tocóme la suerte de llebar luego a Su Mag[esta]d la desdicha nueva. ${ }^{49}$

La presencia de fray Pedro en la muerte de Baltasar Carlos fue bien visto por su reputación de virtud:

Ayúdale [al Príncipe] -escribieron los jesuitas- P. Fray Juan [sic] de Tapia, obispo de Sigüen$\mathrm{za}$, que es un santo varón. El Rey, nuestro señor, se consoló mucho con su venida, que fue esta 
tarde, parece enviado de Dios. El confesor de S.M. dijo no habia visto cosa como la confesión que hizo, su juicio y atención y con tanto conocimiento de la muerte..$^{50}$

La altísima reputación de fray Pedro para la santidad le llevó a ser visto como enviado de Dios. No sólo consoló al Rey el dia de la muerte de Baltasar Carlos, sino también tuvo varias audiencias ulteriores con el Rey:

porque todos aquellos dias me mandaba entrar trataba más de su consuelo. Si bien no levantaba la mano de despachos y significaba alivio con darme audiencias particulares. ${ }^{51}$

El contacto constante con Felipe IV después de la muerte de su hijo llevó más tarde a unas relaciones más intimas entre fray Pedro y el Rey. Las relaciones se continuaron después del regreso de Felipe a Madrid y resultaron en una correspondencia directa entre ambos. Al comentar el epistolario de sor María de Ágreda con Felipe IV Consolación Baranda dice que para sor María de Ágreda su "objetivo no será tanto el de influir en las decisiones políticas concretas como convertir al Rey, de forma que asi la monarquía pudiera alcanzar el favor divino." 52 Las opiniones de fray Pedro de su propia correspondencia con Felipe eran muy similares.

Fray Pedro, como sor María, veía que la mejor manera de mantener la influencia sobre sus corresponsales era parecer ser lo más desinteresado posible al promocionar su propio ascenso. Es una paradoja que para los religiosos la mejor forma de conseguir su ascenso era evitándolo activamente. La reputación de no ser ambicioso convertiría las ambiciones en realidad.

Se tenia que mantener la reputación no sólamente para recibir ascensos, sino también habia que recibir ascensos para mantener la reputación. Si uno no recibía el cargo que le correspondía, eso haría que pensar que era porque no se lo merecia. Esta actitud podemos verla en los papeles de Fernando Ruiz de Contreras ${ }^{53}$, que se encuentran en la Biblioteca Nacional de Madrid, Manuscrito 3.255. Don Fernando escribía al Rey:

Se sirviesse de hazerme m[erce]d de nombrarme por uno de los dellos [léase puestos del Consejo de Indias] pues me allava de los más Antiguos del Conss[ej]o y el ministro más antiguo que avía en el d[ic]ho Cons[ej]o y como quede en Zaragoza por horden de V.M. no bolvé [sic] a instar a V.M. en esta materia aunque era de reputación, pues se nonbrave consejero de Capa y Espada más moderno que si bien su mucha inteligencia y p[ar]tes merecían esta honrra. ${ }^{54}$

Espero que con este estudio breve podamos entender la naturaleza de la reputación en el siglo diecisiete. Podemos ver que las tres definiciones de Shakespeare de la reputación son correctas. La parte inmortal de Cassio, es la parte de él, que no es su realidad física/bestial: es lo que se cree el mundo de él. También vemos en el caso de Medinaceli y doña Antonia de Mendoza que no se pierde una reputación sin admitir haberla perdido. Mientras que los pecados de Medinaceli se mantenían secretos a los ojos del mundo, y se evitaba el escándalo que pudieran causar, la reputación de Medinaceli como moralista quedaba sin manchar. Nos llevaría a creer que la reputación era una imposición falsa e infundada.

Sin embargo, en el caso de fray Pedro, vemos que las cosas no son tan sencillas. No nos es posible saber si la reputación de fray Pedro fue una decepción para los demás porque todas sus acciones guardaban relación con ella. Es imposible saber exactamente si su reputación reflejaba su verdadera naturaleza o la enmascaraba. Está claro que fray Pedro buscaba activamente mantener su reputación de un santo varón como de personaje político desinteresado. Nada de lo que hacia fray Pedro - o que se le veía hacer- contradecía su reputación para la santidad. Su ascenso -llegó a ser Arzobispo de Sevilla - parece que ocurrió a pesar de sí mismo y como consecuencia de su reputación de no querer ascender. Para un hombre de las convicciones religiosas de fray Pedro, yo conjeturaria que quería 
ascender no para verse en tan alta cargo, sino porque consideraba sinceramente que, de esa manera y a causa de sus estudios teológicos, podía guiar la Monarquía Católica hacia la salvación divina.

En el caso de los reyes, sus reputaciones les harían inmortales. Aquí también tenemos un juego de palabras: ¿a qué tipo de inmortalidad se refiere? ¿A la inmortalidad del alma al recibir la vida eterna, o a la inmortalidad de Nerón, por ejemplo, un candidato obvio a la perdición? Lo que ha llegado a ser claro en el curso del estudio es que el concepto del siglo diecisiete de la reputación en la Monarquía Católica excluía la reputación negativa. Nos explica, por lo tanto, por qué Cassio puede perder la reputación en vez de llegar sencillamente a la eternidad por medio del mal.

\section{Notas}

1 Este articulo se basa en mi testis doctoral, titulada Factional Politics at the Court of Philip IV after the the fall of Olivares, presentada en la Universidad de Leeds de Gran Bretaña con fecha de noviembre de 1997. Los examinadores, Dr. Anthony Wright de la Universidad de Leeds y Prof. Terence O'Reilly de la Universidad de Cork de Irlanda, me recomendaron que escribiera este artículo. La tesis trata de examinar el sistema politico de intereses y facciones que existía después de la caida del Conde-Duque de Olivares. Es un área de la historia del reinado de Felipe IV que necesita más investigación. La testis, en principio, examina una facción que operaba en los años criticos de 1646 y 1647. La facción se componia del Duque de Medinaceli, el Duque de Infantado, fray Pedro de Tapia, obispo de Sigüenza, y el secretario del Rey don Francisco de Oviedo. Se basa en un epistolario inédito entre fray Pedro de Tapia y don Francisco de Oviedo, que encontré en la Biblioteca Nacional de Madrid mientras buscaba información sobre Diego de Arce y Reinoso. Es el manuscrito BN MSS 2.276 Cartas del ilustrísimo señor don fray Pedro de Tapia, obispo de Sigüenza y don Francisco de Oviedo. De aquí en adelante, Cartas. En hacer referencia a las cartas cito quién escribe, dónde se ubican si Oviedo no está en Madrid o Tapia en Sigüenza, la fecha en que Oviedo mandó la carta y los folios donde se encuentra.

2 William Shakespeare, Othello. Complete Works, Oxford University Press, 1965, p. 955.

3 John S. Elliott, "A Question of Reputation? Spanish Foreign Policy in the Seventeenth Century.", in The Journal of Modern History, 55, (1983), pp. 475-493, p. 483.

4 Robert A. Stradling, "Introduction: Religion and Reputation - A Universal Cause?", in Spain's Struggle for Europe, 15981668, London, 1994, pp. xv-xxv, p. xviii.

5 Ibid., p. xviii.

6 Bartolomé Clavero, "Delito y pecado. Noción y escala de transgresiones" en Sexo Barroco y otras transgresiones premodernas, Madrid, 1990, pp. 57-89, p. 86.

7 Catalina Fernández de Cordoba fue la hija del Duque de Cardona.

8 Rodrigo Díaz de Vivar de Mendoza y Sandoval era el hijo de Luisa de Mendoza, Condesa de Saldaña, y Diego Gómez de Sandoval, segundo hijo del primer Duque de Lerma. Heredó el título de Duque del Infantado de su abuela, Ana de Mendoza, sexta Duquesa del Infantado.

9 Don Luis de Lauri era un familiar de Infantado de Guadalajara. Servia en la Tribunal de la Contaduría Maior de Cuentas y se ocupaba de administrar las millones en Guadalajara. AHN, Cons., leg. 12.497, s/f. 7. 2. 1648, pago de media anata.

10 Cartas, Oviedo to Tapia, 25. 5. 1647, ff. 227-8.

11 Ibid., Tapia to Oviedo, Berlanga del Duero, 25. 5. 1647, ff. 277-8.

12 Ibid., Tapia to Oviedo, Berlanga del Duero, 25. 5. 1647, ff. 277-8.

13 Esto se refiere a Medinaceli quien fue conocido también como el Duque de Medina y Alcalá o simplemente el Duque de Medina. En la correspondencia de fray Pedro y don Francisco casi siempre se refieren a él como el Duque de Medina.

1000 Papeles de la casa de Medinaceli, f. 26.

Cartas, Oviedo to Tapia, 27. 3. 1647, ff. 245-6.

Después de la muerte de su primera esposa, el quinto Duque de Medinaceli se casó en segundas nupcias con Juana de la Lama y de la Cueva, tercera Marquesa de Ladrada y viuda de Gabriel de la Cueva, quinto Duque de Albuquerque. El primer hijo de estas segundas nupcias fue Gonzalo de la Cerda y de Lama, quien siguió a su madre para ser cuarto Marqués de Ladrada. En 1647 la Marquesa de Ladrada era la esposa del quinto Marqués, Juan de la Cerda Leiva y Mendoza. La Marquesa, Mariana Isabel de Leiva y Mendoza era, también, Marquesa de Leiva y Condesa de Baños en derecho propio. Era prima segunda de su marido Juan de la Cerda.

18 La Duquesa de Medinaceli era hija única de Pedro Girón y su segunda esposa Antonia Portocarrero y Cárdenas, Marquesa de Alcalá de la Alameda. En 1643 Luisa Enriquez de Ribera Portocarrero heredó de su prima, Maria Enríquez de Ribera, el título de Duquesa de Alcalá de los Gazules. A su muerte en Andalucia en 1645, este titulo pasó a su hijo Juan Francisco de la Cerda.

Cartas, Oviedo a Tapia, 27. 3. 1647, ff. 245-6. 
2I Mauro Hernández, A la sombra de la Corona, Madrid, 1996, p. 174.

22 Cartas, Oviedo to Tapia, 19. 12. 1646, ff. 188-91.

23 Ibid., Oviedo to Tapia, 4. 4. 1647, ff. 253-4.

24 Castillo de Bovadilla, Politica para corregidores, Amberes, 1750, p. 375.

Cartas, Tapia to Oviedo, 22. 9. 1646, ff. 148-9.

Carraffa, op. cit., Vol. 15, 1924.

Cartas, Tapia to Oviedo, 2. 3. 1647, ff. 237-8.

Una de las personas que ayudaron a doña Antonia era un hombre llamado Maestro Román. No he podido descubrir quien era.

Se refiere al décimo Conde de Benavente quien se casó en segundas nupcias con doña Antonia de Mendoza.

Cartas, Oviedo a Tapia, 29. 3. 1647, ff. 249-50.

Ibid., Tapia to Oviedo, 17. 4. 1647, ff. 263-4.

La enorme cantidad de este pago -más que la dote ofrecida a Antonia de la Cerda - indica que tanto la dama como el caballero involucrados eran de la más alta nobleza. Nos parece aún más irritante que sea imposible descubrir la información que la señora tenía.

33 No sé que significa esta elección de convento.

34 Se refiere a la intención de tomar órdenes que tenia la parte de Medinaceli.

35 Cartas, Oviedo to Tapia, 5. 6. 1647, ff. 283-6.

36 Ibid., Tapia to Oviedo, Almazán, 5. 6. 1647, ff. 283-6.

37. Pedro de Pacheco Girón, era un patrón de Quevedo y amigo de don Francisco de Oviedo. También era consejero de Castilla y de Cruzada.

38 Su ama era doña Ana de Silva Manrique de la Cerda una prima segunda de Medinaceli. Era la tercera mujer de Diego de Benavides, octavo Conde de Satisteban.

Cartas, Oviedo to Tapia, 10. 7. 1647, ff. 295-6.

Palacio Nacional de Madrid, ca 2651/12 Antonia de Mendoza.

Ibid.

Ibid., Oviedo to Tapia, 28. 4. 1646, ff. 68-9.

Habia dos tipos distintos de dinero en la Castilla del siglo diecisiete. El de metal precioso -plata- y el de metal bajo de ley - vellón.

44 Cartas, Tapia to Oviedo, 2. 3. 1647, ff. 233-6, el ènfasis es mio.

45 Fernando Martínez Gil, Muerte y sociedad en la España de los Austrias, Madrid, 1993, p. 589.

46 Bartolomé Calvero, op. cit., p. 86.

47 Llamaron a fray Pedro a Zaragoza para opinar sobre la introducción de un impuesto nuevo de la harina.

48 Este relato de la muerte se parece mucho al relato de una muerte buena de Juan Santo Tomás, Ayudar a bien morir, Alcalá de Henares, 1645, p. 4.

49 Cartas, Tapia to Oviedo, Zaragoza, 10. 10. 1646, ff. 1545.

50 Memorial Histórico Español, Vol. 38, p. 408.

51 Cartas, Tapia to Oviedo, Zaragoza, 15. 10. 1646, ff. 158-9.

52 Consolación Baranda (Intro.), María de Jesús de Ágreda, Correspondencia con Felipe IV. Religión y razón de Estado, Madrid, 1991, p. 44.

53 Fernando Ruiz de Contreras era Secretario del Rey. Era uno de los más poderosos secretarios del reinado de Felipe IV. A menudo se referían a él como Fernando de Contreras, hecho que ha producido cierta confusión sobre su identidad. Verse Joaquín Pérez Villanueva, Felipe IV y Luisa Enriquez Manrique de Lara, Condesa de Paredes de Nava. Un epistolario inédito, Salamanca, 1986, p. 137, Felipe IV habla de sus gastos secretos y de que los controla Don Fernando de Contreras. Pérez Villanueva dice que "no sabemos más de este Don Fernando, pero de familia y de posición le debe venir ese puesto de confianza." Sin duda se refiere a Don Fernando Ruiz de Contreras quien controló los gastos secretos después de Gerónimo de Villanueva. Verse nota 54.

Bn MSS 3.255 Títulos de la Casa del Marqués de la Lapilla, f. 184.

\section{Bibliografia}

Fuentes inéditas:

Biblioteca Nacional de Madrid

MSS 1.000 Papeles de la Casa de Medinaceli.

MSS 2.276 Correspondencia del llmo. obispo de Sigüenza, don fray Pedro de Tapia con don Francisco de Oviedo. (Cartas) 
MSS 3.255 Títulos de la casa del Marqués de la Lapilla.

MSS 3.643 Genealogía de la casa de Medinaceli.

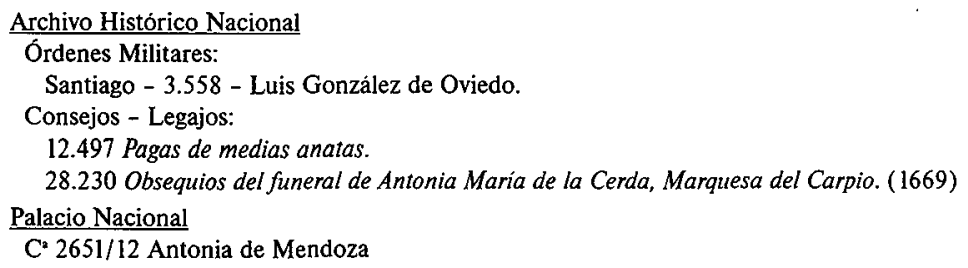

Fuentes impresas:

ÁGreda, Maria de Jesús de, Correspondencia con Felipe IV, Biblioteca de Autores Españoles (BAE), Vols. 108-9, Madrid, 1985. Arteaga y Falguera, Cristina de, La casa del Infantado. Cabeza de los Mendoza, Madrid, 1944.

Asch, Ronald G. and BIRKE, Adolf M. /Eds./, Princes, Patonage and the Nobility. The Court at the Beginning of the Modern Age, c. 1450-1650, London, 1991.

BARANDa, Consolación, (Intro.), Correspondencia con Felipe IV. Religión y razón de Estado, Madrid, 1991.

Castillo de Bovadilla, Politica para corregidores, Amberes, 1750.

Domínguez Ortiz, Antonio, Política fiscal y cambio social en la España de los Austrias, Barcelona, 1984.

ELLIOTT, John Huxtable, "A question of Reputation? Spanish Foreign Policy in the Seventeenth Century", in The Journal of Modern History, 55 (1983), pp. 475-483.

GARCIA CARRAFFA, Alberto y Arturo, Enciclopedia heráldica y genealógica hispana-americana, Vols. 12 (1923), 54 (1937), Madrid. Hernández, Mauro, A la sombra de la Corona. Poder local y oligarquia urbana. (Madrid, 1606-1808), Madrid, 1995.

$J_{A G O}$, Charles, "The Influence of Debt on the Relations between Crown and Aristocracy in Seventeenth-Century Castille", in Economic History Review, XXVI, 2nd series (1973), pp. 218-236.

LOREA, Antonio de, Istoria de la apostólica vida de fray Pedro de Tapia, Madrid, 1676.

MARTÑEZ, Juan, Discursos theológico y politicos, Alcalá de Henares, 1664.

MARTínez Gl, Fernando, Muerte y sociedad en la España de los Austrias, Madrid, 1993.

Memorial Histórico Española, Cartas de Jesuitas, Vols. 18-19, Madrid, 1868-9.

Minguella y ARMEDo, Toribio, Histora de la diócesis de Sigüenza y de sus obispos, Madrid, 1913, Vol. 3, pp. 47-59.

Pérez Villanueva, Joaquin, Felipe IV y Luisa Enriquez Manrique de Lara, Condesa de Paredes de Nava. Un epistolario inédito, Salamanca, 1986.

SANTO TOMÁs, Juan de, Ayudar a bien morir, Alcalá de Henares, 1645.

Shakespeare, William, Othello. Complete Works, Oxford University Press, 1965, pp. 943-976.

Simón DíaZ, José, Dominicos de los siglos XVT y XVII: escritos localizados, Madrid, 1977.

StradLING, Robert A., "Introduction: Religion and Reputation - A Universal Cause?" in Spain's Struggle for Europe, 1598I668, London, 1994, pp. Xv-xxv.

Tomás y Valiente, Francisco y B. Clavero, A.M. Hespanha, J. L. Bermejo, E. Gactoy, C. Álvarez Alonso, Sexo barroco $y$ otras transgresiones premodernas, Madrid, 1990.

\section{POLITIC̄NE RAZSEŽNOSTI UGLEDA NA DVORU FILIPA IV.}

Članek temelji na avtoričini doktorski disertaciji, v kateri preučuje različne politične interese in politične združbe na dvoru Filipa IV. po padcu vojvode Olivaresa. Na treh izbranih primerih, dveh iz posvetnega in enem iz cerkvenega življenja tistega časa, skuša avtorica prikazati velik vpliv družbenega ugleda posameznika na njegov politični status ter, nasprotno, vpliv političnega položaja v javnem življenju na dvig posameznikovega družbenega statusa. 